\title{
INTRODUCTION OF THE EQUALITY PRINCIPLE IN WASTE MANAGEMENT ECONOMICS
}

\author{
Jan Stenis \\ University of Kalmar, Sweden
}

\begin{abstract}
The study illustrates how commonly known business economic models and methods, as well as the Polluter-Pays Principle, can be applied to industrial and construction waste management so as to facilitate environmental optimisation of industrial and construction waste fractionation. Conclusions are drawn stating that the use of altered economic models is viable as a basis for industrial and construction waste assessment. This is aimed at making industry act in a manner truly in accordance with the conception of a sustainable development according to the shift of waste management paradigms proposed by the author.
\end{abstract}

\section{KEYWORDS}

Industrial and construction waste management, Economic models and methods

\section{INTRODUCTION}

The research group lead by Prof. Hogland at the Department of Technology, University of Kalmar, currently has the ambition to heavily increase the exploration of not only technical, chemical and environmental aspects etc. of waste management, but the economy behind the phenomenon as well. Already in the Proposal for research programme in environmental science and technology from August 1999 [1], Prof. Hogland designed the guidelines for how to incorporate financial issues into the research agenda of his group.

This ambition now has resulted in Dr Jan Stenis having presented, first a licentiate dissertation in 2002, and then a doctoral thesis in 2005 under the supervision of mainly Prof. Hogland. The first work dealt with how commonly known business economic methods, models and tools could be adapted for use in industrial waste management in order to improve the environment as well as the corporate profitability and the good will in relation to environmental matters. The second work expanded the ambition to encompass waste from the construction, building and renovation sector as well. As was the case with the licentiate dissertation, the doctoral work pointed in the direction of a big potential existing for applying business administration theory on (industrial and construction) waste management issues [2]. An easy-to-grasp summary of the research performed can be found on Dr Stenis' web page: http://stenis.info [3]. 


\section{METHODOLOGY}

The intention of the study, inter alia, is to present economic models, primarily for short run use, as objects for modifications with the ambition to provide initial outlines of how to make them adapted to mainly practical daily use in waste management. In doing so, after an introduction giving the scientific background, the new scientific approach proposed by $\mathrm{Dr}$ Stenis is outlined in a summarised way. Hereby, the use of different altered economic methods in practice is emphasised involving shadow prices. Next, in an explanatory section, important matters on variable and fixed costs, revenue and the possibility to use environmental impact weights, is taken up. Thereafter, the conclusions are given encompassing a list of the outcome and benefits of the doctoral work of Dr Stenis. Finally, possible directions for further research are sketched out.

\section{THE NEW SCIENTIFIC APPROACH}

Disposal of industrial waste often creates serious environmental problems. In the long run, these problems need to be eliminated, or markedly reduced, so that nature can be kept as clean as possible. This calls for the clarification and establishment of links between company profits, as expressed in consolidated profit and loss accounts, and both the avoidance and proper utilisation of waste. A new way of looking at waste, or, a shift of waste management paradigms, is needed. Otherwise, the process of achieving environmental cleanliness in industry can be painfully slow. A comprehension that is argued for here, involves equating industrial waste with normal products in terms of the allocation of revenues and costs, an approach that is termed the "equality principle" [4]. A framework upon which such a principle, oriented to the maintenance of a sustainable development, can be based is further developed here.

In line with this, this study suggests that the waste fractions studied are to be regarded as a kind of company output. This is mathematically considered by adding the sum of the actual quantities of a certain kind of waste belonging to a certain waste fraction set up scenario, to the quantity of normal production output in the denominator in the following expression (1) which is to be used for the allocation of revenues and costs to a certain waste fraction through multiplication by the costs or revenues in question that are to be allocated by splitting them up in their proper proportions. The current waste fraction thus represents a new, substantially larger, cost, a so called shadow cost or shadow price which, if fully taken into account, imposes very strong financial incentives to drastically reduce the waste in question. Expression (1) is the model representation of the equality principle expressing its financial implications and that is termed the model for Efficient Use of Resources for Optimal Production Economy (EUROPE).

A

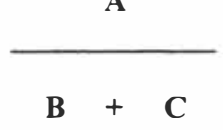

where

$A=$ quantity of the waste fraction in question produced

$\mathrm{B}=$ quantity of normal product output

$\mathrm{C}=$ sum of the quantities of the different waste fractions considered 
One must define a suitable production or administrative unit to apply expression (1) on. This suitable unit can be everything from e.g. the entire company via divisions or profit centre workshops to an individual machine or any other level of the production system, depending on the circumstances [5].

\section{EXEMPLIFICATION OF THE USE OF THE NEW SCIENTIFIC APPROACH IN PRACTICE}

In Figure 1, the flow of input, products and waste through the company "black box" is illustrated in a schematic way.

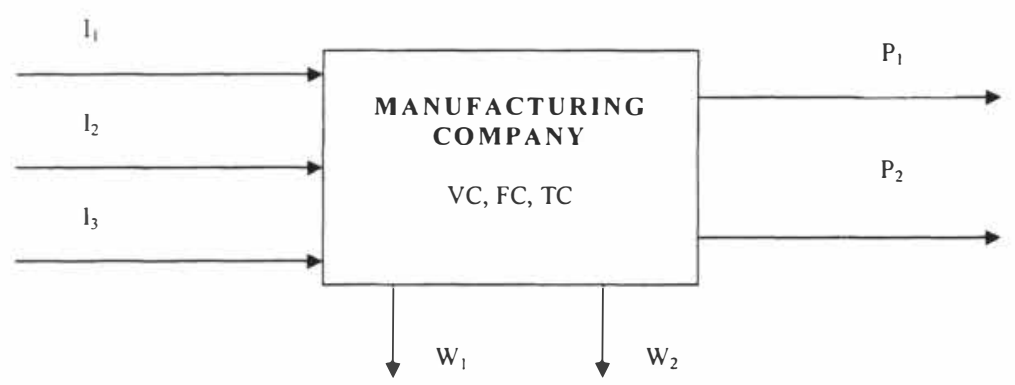

Figure 1. The flow of input, products and waste through the company "black box".

where

$I_{1}=$ Input good No. 1. Unit: tonnes, litres, value etc.

$\mathrm{I}_{2}=$ Input good No. 2

$\mathrm{I}_{3}=$ Input good No. 3

$\mathrm{P}_{1}=$ Product output good No. 1. Unit: tonnes, litres, value etc.

$\mathrm{P}_{2}=$ Product output good No. 2

$\mathrm{W}_{1}=$ Waste bad No. 1. Unit: tonnes, litres, value etc.

$\mathrm{W}_{2}=$ Waste bad No. 2

$\mathrm{VC}=$ Variable cost. Unit: $\$, €, \mathrm{SEK}$ etc.

$\mathrm{FC}=$ Fixed cost

$\mathrm{TC}=$ Total cost $\mp \mathrm{VC}+\mathrm{FC}$

Definitions

$T P=$ Total product output goods $F \Sigma P_{x}=P_{1}+P_{2}+,,+P_{n}$

$T W=$ Total waste output bads $=\Sigma W_{x}=W_{1}+W_{2}+,,,+W_{n}$

$\mathrm{TR}=$ Total revenue from the waste fraction $\mathrm{W}_{\mathrm{x}}$

The EUROPE model gives PF

$\mathbf{P F}=$ The Proportionality Factor $=\mathbf{W}_{\mathbf{x}} /[\mathbf{T P}+\mathbf{T W}]$

(Compare expression (1) above) 
The Environmental Adjustment Cost $\approx=$ EAC $=$

$=$ all costs connected with making the production processes of a company environmentally friendly $=$

$=$ net present value (NPV) of profit (loss) from the investment $=$

$=$ present value of revenue - investment cost

\section{SCHEMATIC PRINCIPLES FOR ALLOCATION OF SHADOW PRICES TO WASTE FRACTIONS USING DIFFERENT ECONOMIC METHODS}

\subsection{Cost-Benefit Analysis}

5.1.1 The method of overhead rates based on normal capacity

TR

$-\mathrm{FC}^{*} \mathrm{PF}$

- $\mathrm{VC} * \mathrm{PF}$

$=$ Amount to be allocated to the waste fraction $\mathrm{W}_{\mathrm{x}}$

TC/item F [Estimated VC / Calculated quantity of items]

+ [Estimated FC / Normal quantity of items]

5.1.2 The average cost estimation method

$$
\begin{aligned}
& \mathrm{TR} \\
- & \mathrm{FC} * \mathrm{PF} \\
- & \mathrm{VC} * \mathrm{PF} \\
= & \text { Amount to be allocated to the waste fraction } \mathrm{W}_{\mathrm{x}} \\
& \text { TC/item }=[\mathbf{F C}+\mathrm{VC}] / \mathrm{TW}
\end{aligned}
$$

It is to be noted that the possibilities for applying the equality principle (Stenis, 2002) on construction waste management are biggest for the average cost estimation method.

5.1.3 The equivalent method of cost estimation

$$
\begin{aligned}
& \mathrm{TR} \\
- & \mathrm{FC}{ }^{*} \mathrm{PF} \\
- & \mathrm{VC}{ }^{*} \mathrm{PF} \\
= & \text { Amount to be allocated to the waste fraction } \mathrm{W}_{\mathrm{x}}
\end{aligned}
$$

where

$$
\mathbf{P F}=\mathbf{W}_{\mathbf{x}} /\left[\left(\Sigma\left(\mathbf{P}_{\mathbf{x}}{ }^{*} \mathbf{E} \mathbf{R}_{\mathbf{x}}\right)\right)+\mathbf{T W}\right]
$$

$E_{x}$ F The equivalent rate for a particular product $P_{x}=$ $=[$ Normal cost per unit for a given product $] /$

/ [Normal cost per unit for the product with the lowest cost per unit] 
5.1.4 The absorption costing method

TR

- TC estimated using the absorption costing method * PF

$=$ Amount to be allocated to the waste fraction $\mathrm{W}_{\mathrm{x}}$

\subsubsection{The Activity-Based Costing ( $\mathrm{ABC}$ ) method}

TR

- TC estimated using the ABC method * PF

$=$ Amount to be allocated to the waste fraction $\mathrm{W}_{\mathrm{x}}$

\subsection{Contribution margin analysis}

Income from sale of the fraction sold

- Variable cost of the fraction sold $=\mathrm{VC} * \mathrm{PF}$

$=$ Contribution margin covering the fixed cost

- Specific fixed cost of the fraction in question $=\mathrm{FC} * \mathrm{PF}$

$=$ Contribution margin after deduction of costs traceable to the fraction $=$

$=$ Operating income (or contribution margin)

Operating income per unit of waste fractiona Operating incomed $\mathbf{W}_{\mathbf{x}}=$

= Amount to be allocated to each unit of the waste fraction $\left(W_{x}\right)$

In the case of $\mathrm{n}$ waste fractions, the total contribution margin can be calculated as follows:

$$
\mathrm{CM}_{\mathrm{tot}}=\Sigma\left(\mathrm{CM}_{\mathrm{j}} \mathbf{x}_{\mathrm{j}}\right)
$$

Where

$\mathrm{CM}_{\mathrm{tot}}=$ Total contribution margin of the $\mathrm{n}$ waste fractions

$\mathrm{CM}_{\mathrm{j}}=$ Contribution margin per unit of waste fraction $\mathrm{j}$ calculated using expression

(1) involving shadow prices

$x_{j}=$ The amount of tonnes, litres etc. of waste fraction $\mathrm{j}$

$x_{j} \geq 0, j=1,2,3, \ldots, n$

\subsection{The Polluter-Pays Principle}

Profit (loss) from the investment per unit of waste

$=[\mathbf{E A C} * \mathbf{P F}] / \mathbf{W}_{\mathbf{x}}=$

$=$ Amount to be allocated to each unit of the waste fraction $\left(W_{x}\right)$

\subsection{Joint production theory}

Joint production theory, which among other things concerns the optimal output proportions to aim at obtaining when desirable products and wastes are jointly produced in the same process, makes frequent use of the linear programming technique. Application of this method involves considering there to be different possible scenarios. A particular waste fraction is studied within a given production scenario, one which involves in part a set of different waste fractions with which various revenues and costs are associated. The outcome of the 
profitability analysis for a given fraction guides the decision of whether the fraction in question is to be the object of separation. Such assessments are performed again for any further fraction within the set of fractions to be examined in terms of profitability. In any given scenario, therefore, a new assessment of profits and losses is required for each further fraction considered.

Note that since it is a question of making a choice between different products that can be produced, each product and the wastes related to it need to be regarded as a unit. It is also assumed that the quantities of various wastes related to a particular product are known and are constant per unit of time. This allows the problem to be expressed in the following way, which is adapted to the production of waste:

Find the values of $x_{1}, x_{2}, \ldots, x_{n}$ that will

$$
\operatorname{maximize} z=a\left(p_{1}{ }^{\prime}+p_{1} ’\right) x_{1}+\left(p_{2}^{\prime}+p_{2} ’ '\right) x_{2}+\ldots+\left(p_{j}^{\prime}+p_{j}^{\prime \prime}\right) x_{j}
$$

where

$\mathrm{p}_{\mathrm{j}}{ }^{\prime}=$ profit (or loss, which produces a negative value) per unit of the product $\mathrm{j}$ or of the input

$\mathrm{p}_{\mathrm{j}}{ }^{\prime}=$ profit (or loss, which produces a negative value) from all the waste related to one unit of the product $\mathrm{j}$ or of the input $\mathrm{j}$,

subject to the following constraints

$$
\begin{aligned}
& a_{11} x_{1}+a_{12} x_{2}+\ldots+a_{1 n} x_{n} \leq b_{1} \\
& a_{21} x_{1}+a_{22} x_{2}+\ldots+a_{2 n} x_{n} \leq b_{2} \\
& \cdots \\
& a_{m 1} x_{1}+a_{m 2} x_{2}+\ldots+a_{m n} x_{n} \leq b_{m}
\end{aligned}
$$

where

$\mathbf{x}_{\mathrm{j}} \geq \mathbf{0}, \mathbf{j}=\mathbf{1}, \mathbf{2}, \ldots, \mathbf{n}$.

$\mathrm{a}_{\mathrm{mn}}$ are constant coefficients of production

This allows the most profitable product mix of the $\mathrm{n}$ products and the related wastes to be calculated, and also the total profit to be estimated by multiplying the calculated profitmaximizing amounts of the product by the marginal contribution of each of the $\mathrm{n}$ products and the related wastes. Mathematically, this can be expressed as follows:

Find the values of $x_{1}, x_{2}, \ldots, x_{n}$ that will

$$
\begin{aligned}
& \text { maximize } \mathrm{CM}_{\mathrm{Tot}}= \\
& =\left(\mathrm{CM}_{1}{ }^{\prime}+\mathrm{CM}_{1}{ }^{\prime \prime}\right) \mathrm{x}_{1}+\left(\mathrm{CM}_{2}{ }^{\prime}+\mathrm{CM}_{2}{ }^{\prime \prime}\right) \mathrm{x}_{2}+\ldots+\left(\mathrm{CM}_{\mathrm{j}}{ }^{\prime}+\mathrm{CM} \mathrm{M}_{\mathrm{j}}{ }^{\prime \prime}\right) \mathrm{x}_{\mathrm{j}}
\end{aligned}
$$

where

$\mathrm{CM}_{\text {Tot }}=$ total marginal contribution of the product and waste mix

$\mathrm{CM}_{\mathrm{j}}{ }^{\prime}=$ marginal contribution per unit of the product $\mathrm{j}$ or of the input $\mathrm{j}$

$\mathrm{CM}_{\mathrm{j}}$ " = marginal contribution from all the waste related to one unit of the product $\mathrm{j}$ or of the input $\mathrm{j}$, 
subject to the following constraintsa

$$
\begin{aligned}
& a_{11} x_{1}+a_{12} x_{2}+\ldots+a_{1 n} x_{n} \leq b_{1} \\
& a_{21} x_{1}+a_{22} x_{2}+\ldots+a_{2 n} x_{n} \leq b_{2} \\
& \ldots \\
& a_{m 1} x_{1}+a_{m 2} x_{2}+\ldots+a_{m n} x_{n} \leq b_{m}
\end{aligned}
$$

where

$\mathbf{x}_{\mathrm{j}} \geq \mathbf{0}, \mathbf{j}=\mathbf{1}, 2,3, \ldots, \mathrm{n}$.

$a_{m n}$ are constant coefficients of production

What is new in this approach is the maximization stipulated in (13) and (16), which reflects the assumption of a product and the related wastes representing a unit [3].

\section{EXPLANATORY COMMENTS}

The FC is sometimes difficult to define since it may not be clear which part of the total FC should be allocated to a particular waste fraction. It may be a question of splitting the total FC into parts representing different types of waste. The most natural FC to be allocated to a waste fraction is that for the annual depreciation of equipment and machinery used to separate that fraction. Apart from this, the FC can consist of factors such as interest, depreciation, rent for facilities and the cost of electric or other types of power, for the time period in question.. Wages are usually considered as fixed costs and should thus be apportioned between the waste fractions. Examples on bases for the apportioning are the weight or the volume of the waste fraction considered, the quantity of raw materials employed or the time involved in producing the waste fraction of interest under normal conditions.

The VC of a particular waste fraction that is separated depends on the following factors in particulara(i) the amount of manpower or handling time required to collect the waste fraction in question, (ii) the cost of the raw materials and the energy used in the production process in which the waste is produced, and (iii) the cost of ridding the company of the waste material. If the VC directly associated with a given fraction is known, this cost should of course be used. If not, costs can be allocated, just as they were above for the FC, in proportion to the weight or volume of the waste fraction considered, or the amount of raw material used or the time required to produce it.

The TR for a given waste fraction is a function of factors such as the followinga(i) the selling price of the waste, (ii) the value of reusing or recycling it, (iii) the value of the energy extracted if it is incinerated, i.e. a saving in energy that must otherwise be purchased externally, (iv) the saving of fuel, and (v) the avoidance of taxes and/or fees levied on landfilling the waste. If the TR for a particular fraction is known, this should, of course, be used. If it is not, this study proposes that it should be calculated using expression (1), or the estimated total income arising from the waste fraction in question should be divided by the amount of the waste fraction produced during the time period in question.

Although the application of the EUROPE model as expressed in (1) to the methods discussed above redistributes some of the cost of normal products to wastes, without this necessarily resulting in any increase in total cost for the company, it does not directly link the avoidance of wastes with the incentive to reduce total costs, as specified in the consolidated profit and 
loss account used for business purposes. However, this study proposes that weighting can be used to adjust the costs associated with a particular type of waste to its environmental impact, based on scientific evidence and/or in terms of overall societal aims. For example, a factor 1.2 can be multiplied with the initially obtained shadow cost if a certain waste fraction is regarded to motivate a $20 \%$ mark up to provide an extra incentive to reduce its not wanted existence. What can be termed "environmental shadow prices" should thus be used in combination with the cost allocation principle in defining environmental standards.

Even without the use of such environmental impact weighting, the cost allocation principle is useful internally as a means of redistributing costs associated with waste between different departments of a company. This results in a form of competition between different production units, enhancing environmental improvement and profit. This gives companies an incentive to reduce wastes in order to improve their contribution margin estimates. This improvement incentive has impact on short-term product cost estimates, for example, and thus on budgets and on forecasts used as a basis for loan applications, for example, and on information to company stakeholders [3].

\section{CONCLUSIONS}

As regards the general industrial applicability, the findings point at the fruitful possibility to modify commonly used cost-benefit estimation methods including the PPP in an industrial waste management context by the use of the equality principle introduced. As regards the construction waste management applicability, there exists a big potential for applying the equality principle introduced to a construction waste management context.

The findings point in the direction of a high degree of construction waste management applicability in the real world industrial context. In particular this statement is relevant for the average cost estimation method but also, to a much lesser extent, for the Polluter-Pays Principle application approach. In Table 1 , the outcome and benefits of the doctoral work of Dr Stenis are presented as regards a) companies, b) environment and c) society.

\section{FURTHER RESEARCHES}

\section{Improvement of the efficiency in the waste management for real estates at the construction, administration and demolition stage}

The objective is to improve the efficiency in the construction related waste management for real estates. The results from Dr Stenis' previous research regarding economic models for waste management in industry and the construction business should be applied on the flow of matter (for example construction waste) as well as energy (for example waste heat) through a building object. Six sub projects are supposed to mirror consecutive events in a projects' life cycle encompassing: 1) improved control from planning and design; 2) improved environment and societal economy through use of key performance indicators; 3) sustainability promoting site working routines; 4) the construction stage facilitated by $\mathrm{Dr}$ Stenis' previous works; 5) application of Dr Stenis' previous works on different kinds of construction objects, and; 6) reversed logistics 


\section{Table 1. Outcome and benefits of the doctoral work of Dr Stenis.}

\section{Outcome and benefits of Dr Stenisa work as regards companies}

1 Elaboration of a principle for the estimation of waste-related industrial company costs and revenues.

2 Establishment of a basis for the estimation of the "full" company cost and estimation of the "true" company business financial result.

3 Implications of industrial cost-saving incentives.

4 Improvement of the short-term, corporate economy generally.

5 Saving of raw materials, reduction in time required for handling and less administration of the waste and less wear on the machinery, etc.

6 A positive impact on the balance sheets due to improved environmental goodwill.

7 Enhanced status of industrial and construction waste.

8 Possible increase in the use of prefabricated and made-up construction material leading to higher profits and better quality.

Outcome and benefits of Dr Stenisa work as regards the environment

1 Less waste produced due to reduction in the current wastes at the source.

2 More environmentally friendly industrial production.

Outcome and benefits of Dr Stenisà work as regards society

1 A basis for e.g. waste-related official recommendations and demands, and voluntary environmental agreements.

2 A generally improved environment leading to an improved quality of life.

3 An environmentally improving increase in the gross domestic product (GDP).

4 An attempt to provide the part of society interested in waste management with an economic review theory adapted to industrial and construction waste management.

5 A pioneering attempt as to launch a proposal for a shift in the view of waste management.

6 General environmental and financial advantages for society at large.

7 Prevention of the common misuse of resources in society.

\section{Sustainable building indicators}

A field of research that has lately attracted a certain amount of attention is the development of sustainable building indicators. These may be based on the principle for equality between residual products and goods in mainly financial terms developed earlier. It would be suitable to investigate how the equality principle, in the design stage as well as during the erection and operation of a building, can be used for monitoring the sustainable flow of resources through the building in order to increase the efficiency. In particular, the possibilities to develop indicators for waste (reused, recycled, energy production, disposal and special waste) should be studied.

\section{Modification and application of management tools}

Existing models for waste management usually lack clear financial incentives for implementation of waste reducing means of control. Therefore, the question is how existing theoretical management tools can be modified and applied regarding a general need to reduce the existence of the waste phenomenon through giving the different actors strong financial incentives to implement a sustainable waste policy. The main purpose in this context would 
be to show how the mainly prevailing management tools, methods and models can be adapted according to the equality principle with the aim of laying the foundation for design of new control devices for implementation of sustainable official authority policies for management of resources and wastes and for the energy sector as well.

\section{Principles for construction object disassembly for reverse logistics}

A field of research that is more directed towards the end of the lifetime of a building is so called reverse logistics. In this study, this term refers to the time when a construction object is disassembled and the different components must be taken care of, this involving a substantial logistical effort to organise the transportation of the different parts to their final destinations. Therefore, it should be studied how concrete principles for construction object disassembly can be elaborated in order to make the reverse logistics process more efficient based on the equality principle introduced.

\section{Application of the equality principle on different types of construction objects}

Finally, it would be worthwhile to examine the economic consequences that occur when the equality principle, primarily through the average cost estimation method, is applied to other construction objects than ordinary houses, examples being industry buildings and infrastructural objects.

\section{ACKNOWLEDGEMENTS}

The author would like to thank Professor William Hogland and Project Assistant Viatcheslav Moutavtchi, Department of Technology, University of Kalmar, Sweden, for most useful input and comments.

\section{REFERENCES}

[1] Hogland, W., 1999. Proposal. Research programme in environmental science and technology. Report No. 110. Department of Technology, University of Kalmar, Kalmar, Sweden.

[2] Prof. William Hogland's home page: http://homepage.te.hik.se/personal/thowi/economic.htm

[3] Dr Jan Stenis' home page: http://stenis.info

[4] Stenis, J., 2002. Industrial Waste Management Models - A Theoretical Approach. Licentiate dissertation. Department of Construction and Architecture, Division of Construction Management, Lund Institute of Technology, Lund University, KFS AB, Lund, Sweden.

[5] Stenis, J., 2005. Industrial Management Models with Emphasis on Construction Waste. Doctoral thesis. Department of Construction and Architecture, Division of Construction Management, Lund Institute of Technology, Lund University/ Department of Technology, University of Kalmar, Intellecta Docusys, Lund, Sweden, p.56a 